\title{
Trade and Economic Cooperation of BRICS: Problems and Prospects
}

\author{
I. Z. Yarygina \\ Dr. of Economic Sciences, Professor, \\ $M G I M O(U)$ under the Ministry Foreign Affairs of Russia Federation; \\ Head of the Chair Economics and Banking, Moscow, Russia \\ A. V. Zhiglyaeva \\ Researcher, Department of Global Economy and Finance, \\ Financial University under the Government of the Russian Federation \\ Moscow, Russia

\section{O. V. Vershinina} \\ Candidate of Economics, Associate Professor, \\ Head of the Department of Finances and Bank Business \\ Russian New University, Moscow, Russia

\section{Yu. A. Kuvshinova} \\ Candidate of Economic, Associate Professor, \\ Head of the Department of Finances and Bank Business \\ Russian New University,Moscow, Russia
}

DOI: https://doi.org/10.36941/ajis-2020-0114

\section{Abstract}

The subject of this study is the legal and financial features of the BRICS trade and economic cooperation and the practice of their application in modern conditions. The purpose of this article is to identify problems that impede the effective development of economic relations and put forward proposals for their improvement. The study showed that the BRICS countries have significant reserves for multilateral cooperation and support of trade and economic relations. In this regard, harmonization of trade and economic relations of partner countries is necessary, in order to solve strategic problems and improve the living standards of the population. It is shown that simplifying the access of entrepreneurs to credit, tax incentives for exporters of industrial goods, flexible conditions for direct and indirect financing of projects and programs, expanding the participation of BRICS development banks and institutional investors contributes to the progressive development of national economies and improving trade and economic relations of BRICS. For research purposes, IBOV INDEX (Brazil), CRTX INDEX (Russia), SENSEX INDEX (India), SHCOMP INDEX (China), JALSH INDEX (South Africa) and Bloomberg platform (WEI, DES, GP, XLTP XCIT, MEMB) materials were used. Evaluation of data in key sectors of the BRICS economies showed the existence of interconnectedness and interdependence of the BRICS trading floor indices - sources of direct financing for trade and economic cooperation of partner countries. Correlation analysis and cointegration of time series confirmed a solid foundation for stimulating multilateral cooperation of the BRICS, including on the basis of interstate support for business entities and expanding the participation of institutional investors in ensuring sustainable development of the BRICS. It is concluded that the results of the study can be used in developing measures of interstate support for trade and economic cooperation of BRICS in modern conditions.

Keywords: BRICS, trade and economic cooperation, interstate support, institutional investors, stock market, indices 


\section{Introduction}

Trade and economic cooperation of BRICS (Brazil, Russia, India, China and South Africa) is one of the priority areas of the Economic Partnership Strategy of member countries. In the list of key objectives of this Strategy, an important place is played by promoting trade cooperation, expanding access to the stock markets of member countries and diversifying investment cooperation. It was noted that active trade cooperation, along with other areas, is designed to strengthen balanced and inclusive economic growth, as well as increase the level of international competitiveness of the BRICS economies, which account for $17,3 \%$ of world trade in goods, $12,7 \%$ of world trade in services, $21 \%$ of global gross domestic product (GDP).

Currently, the process of the development of trade - economic relations and expansion of use of national currencies of BRICS countries in ensuring economic relations, which of the following reasons: the output of the currency outside the country, which is the result of the development of trade economic contacts of the partner countries; important sectors of the circulation of the national currency, in countries outside of their vehicles, are trade, financial services and tourism; some national currencies of partner countries are able to perform the functions of money abroad, and to ensure the implementation of international cooperation; use of national currencies of the BRICS affect the development of trade and cross-border regions and neighboring "third countries": Mongolia, Vietnam, the countries of the Eurasian Economic Union, etc. increased use of national currencies in international economic relations of the countries - participants of world economic relations - is largely due to the development of trade cooperation, which plays an important role in ensuring interaction between the parties. Areas of interactions are energy, oil products, wood processing, agriculture, machinery and equipment, production of construction materials. Good prospects for the use of national currencies remain in the sphere of export - import operations, development of infrastructure, transport, medicine, new technologies, environmental protection. From our perspective, the use of national currencies is associated with the state of trade and economic cooperation, which depends on the conditions of economic cooperation and political will. In this regard, the development of mechanism of publicprivate partnerships, and the creation of joint enterprises, with participation of business entities of the BRICS, play an important role. State support for commercial, industrial centers, aimed at expanding trade ties, can open up broad prospects, including in the framework of implementation of investment projects, joint ventures, the activities of small and medium enterprises. The basis of the interaction of the parties is the legal framework of BRICS and the agreement between the central banks of partner countries (reached in 2007) on the increasing use of national currencies, including in the service sector. The infrastructure of the central banks of member countries, stock markets, development banks, with the participation of BRICS, is currently operating. It is important to note the positive dynamics of the interaction of the BRICS New Development Bank (NDB) with the participants in the trade and economic relations of BRICS. In order to implement the agreements, it is important to use the levers of agreed benefits and preferences, as the main incentive for entrepreneurs is "profitable business".

\section{Fundamentals of BRICS Economic Cooperation in Trade}

The purposeful desire to expand and strengthen ties in the field of trade and investment is gaining more and more clear guidelines and is reflected in the main BRICS documents. On July 9th 2015, the BRICS Economic Partnership Strategy up to 2020 (project of the Ministry of Economic Development) was adopted at the initiative of Russia, which is aimed at expanding multilateral business cooperation, in order to accelerate social and economic development and increase the competitiveness of BRICS participants in the world economy in key areas of world economic relations: trade and investment, manufacturing and mining, energy, cooperation in agriculture, science, technology, innovation, finance, tourism and etc. The project is currently being implemented on the basis of the existing ministries in the member countries: a system of interaction and agencies listed in the Strategy for Economic Partnership areas. Representatives of BRICS make proposals on the areas of cooperation 
specified in the Strategy for Economic Partnership for the purpose of discussion within the Working Groups and decision-making at the annual BRICS Summits.

The actual task of development of multilateral trade cooperation in the BRICS format provided in the Declaration of October 16th 2016, adopted at the VIII summit of the BRICS in Goa, India. The leaders expressed confidence in the need to further stimulate the growth of regional integration, with the strict observance of the principles of openness and equality, in order to ensure the development of investment, trade and commercial ties. The Declaration of Goa emphasizes the importance of public and private infrastructure investment, the strengthening of multilateral and non-discriminatory, multilateral trading system, consistent implementation of key economic initiatives, including the development of cross-border e-Commerce and support to small and medium-sized businesses. It is also noted the importance of strengthening cooperation between the customs agencies of the BRICS on the basis of the agreed positions of the countries. With the development of trade-economic cooperation between the partner countries and the implementation of the tasks set in the Strategy of Economic Partnership of the BRICS in October 2016, India hosted the First exhibition-fair of BRICS TRADE FAIR. The Russian exposition was attended by 43 companies, including: JSC "Russian Export Center", JSC "RVC", FMBA, JSC "Sberbank", the "Russian Helicopters" holding company, JSC "Russian Railways" and others. The company DNBD Interactive Forums, India was also created by the information coordinator of the Russian exposition in New Delhi. The exhibition - fair has created new opportunities for the BRICS cooperation in trade, investment, defense industry, finance, agriculture, which was further developed in the investment program of the NDB BRICS. The exhibition was held at the meeting of the Business Council of member countries of BRICS. It seems appropriate to keep the format of business contacts between economic entities of the BRICS in the framework of exhibitions, forums, business meetings.

In turn, in the BRICS Amoy Declaration of September 4th 2017, the attention of countries is focused on the formation of the BRICS Working Group of countries in the field of electronic commerce, the creation of the BRICS Electronic Ports Network, the phased implementation of cooperation framework programs, roadmaps and the basic principles of trade and investment facilitation. It is important to note that partner countries have taken a course towards enhancing cooperation in the field of public-private partnership (PPP). The necessity of developing the potential of BRICS interbank cooperation, jointly resolving issues of lending in national currency and cooperation, in the field of sharing credit-rating data, is emphasized. At the 2017 summit, the BRICS leaders agreed to maintain close ties, in order to develop cooperation in the monetary and financial sphere, in accordance with the mandate of the central banks of each country, including through currency swap transactions, settlements in the national currency and direct investments in the national currency, as well as to study other modalities of cooperation in the field of facilitating the establishment of links between markets, infrastructure and financial integration, in the interests of ensuring interconnected development.

The Johannesburg Declaration of the Tenth BRICS Summit, adopted on July 26th 2018, emphasizes the importance of forming and actively using the specialized BRICS agricultural research platform, the development of industrial coastal zones, improving the predictability and security of foreign trade relations, the need to ensure industrial development, and solving infrastructure problems, including expanding financing for infrastructure development. The indicated areas of cooperation are directly related to the expansion of interstate support for trade and economic ties of the BRICS. The Johannesburg Declaration also emphasized the prospect of introducing block chain technologies (distributed registry) and noted their role in adapting to the rapidly-developing Internet economy. In accordance with the declaration in question, the countries commit themselves to further expand their strategic partnership for the benefit of the BRICS people through a more equitable international order. In this regard, it is important to note the initiative to create PartNIR (BRICS Partnership on New Industrial Revolution) and, in particular, the establishment of the BRICS Partnership Advisory Group. In December 2018, the first meeting of the BRICS PartNIR advisory group was held in South Africa, during which the parties approved a concept that envisages expanding the interaction of the parties, including in the field of trade, in order to help solve key tasks of the 
development of national economies.

In addition, the BRICS countries expressed their intention to contribute to the development and search for solutions to key tasks in the framework of the Brazilian Declaration of 2019. In September 2019, the second meeting of the PartNIR advisory group was held in Brasilia, in which the Work Plan for Further Actions was approved. In October 2019, the Ministry of Economic Development presented the concept of an updated BRICS Economic Partnership Strategy until 2025, and in February 2020, draft Memorandum of Cooperation and an updated PartNIR Work Plan were prepared, which are to be approved in the year of the Russian BRICS chairmanship. Currently, BRICS countries do not have PartNIR obligations. However, work is underway to coordinate the interaction of the parties, within the framework of the Russian chairmanship of the BRICS, in 2020.

Issues related to the goals and objectives, incentives and obstacles in the field of trade and economic cooperation of the BRICS are also discussed at meetings of ministers and senior officials, as part of meetings of working groups and experts. For example, on the basis of the eighth meeting of the BRICS economics and foreign trade ministers in Magalisburg (South Africa) on July 5th 2018, priority areas for multilateral cooperation are outlined: prospects for trade in value-added goods, features of electronic commerce, a unified approach to the development of trade in services by countries. Promotion of the use of national currencies in ensuring trade cooperation between countries is reflected in the materials of the meetings of the finance ministers and the managers of the central banks of BRICS.

The presented initiatives contribute to the expansion of multilateral cooperation of the countries - members of the interstate association. Modern statistics from international organizations, and also materials from BRICS publications, confirm the existence of significant achievements in the field of trade. According to the BRICS Business Council, for the period 2001-2019, there was a significant increase in the share of trade within the BRICS (intra-group), in the total foreign trade turnover of member countries, from $6,2 \%$ to $11,2 \%$. From 1990-2019, the BRICS share in world production increased from $5,4 \%$ to $22,8 \%$. However, the growth of the BRICS share, excluding China, was less significant (from 3,7\% to 7,9\%) [UNCTAD, 2019]. It should be noted also that an important role in the development of BRICS trade and economic relations belongs to institutional investors and their economic activities backed by the strategic interests of member- states.

\section{Institutional Investors as a Factor of Development of BRICS Trade and Economic Cooperation}

Practice has shown that sovereign investors play an important role in the development of trade economic cooperation, contributing to the objectives of domestic and foreign policy of the countries participants of world economic relations. Currently, when competing for sovereign investors, the BRICS face stiff competition and high economic and political risks. It should be noted that sanctions pressure, as a method of competitive struggle for markets and spheres of influence, remains, which is not conducive to the extension of access to Western loans, direct investment and technology. In addition, the result of a complex epidemiological situation of a global pandemic is slowing the progressive development of strategic sectors of the economies of partner countries. In these circumstances, an important role, in the optimization of trade and economic cooperation, the BRICS must play is development of institutions. It seems appropriate to note that their participation in the business processes stimulates the development of innovative industries, contributes to the reengineering of production processes and the development of multilateral trade, by mobilizing sources of credit and financing of development programs in the interests of economic entities. Overall, the national economies (at the BRICS summit) provided a historic opportunity to modernize basic industries and the transition to new management principles, including international economic relations, in the conditions of overcoming the consequences of the epidemiological challenges and inter-support among the BRICS economies. In this situation, it is important to "take a course" on full volume development of production and processing of products, the formation of production chains 
and flexible promotion of trade and economic cooperation between partner countries. It should be noted that long-term binding of the state budget, to the price of the hydrocarbon feedstock, contributes to the formation of a new technological mode of operation of the new industrial revolution. The market price of hydrocarbons', as is known, depends not only on the market and the demands of the global economy and political risk. The price of oil becomes a tool of "big politics" pressure on the sovereign interests of the countries, which affects the state of the oil industry and its exports, the financial sector and national currency. The high level of lending rates is not aimed at credit expansion of production facilities, trade financing and is primarily associated with "inflation expectations" in the economy.

In this regard, in order to optimize the lending programs of trade and economic development of key sectors of the BRICS economies, it seems appropriate to follow the path of substitution of foreign borrowing for domestic investment resources of institutional investors, the BRICS. Important supplements to state support of economic development are resources of specialized funds and reserves, formed to promote the development of BRICS. Use of funds development funds identified the legal framework of BRICS and the legislation of each member country. For example, in the Russian Federation, the Reserve Fund provides a balanced budget and National Welfare Fund (NWF) of Russia contributes to the implementation of sustainable projects and the development of the banking sector. In addition, the Russian Federation formed other Federal funds and agencies, the purpose of which is to promote economic development and investment programs.

The Investment Fund of the Russian Federation, the Russian Direct Investment Fund (RDIF), the Fund of Housing and Communal Services, invest funds of constituent entities of the Russian Federation, the Agency for Strategic Initiatives(ASI), the Deposit Insurance Agency(DIA), the Federal Center for Project Finance (FCPF), etc. The activities of these funds are directed to the realization of strategic projects. It would also be appropriate to strengthen the role of private investment funds, including large corporations and banks, especially development banks, to enhance financing of trade cooperation and modernization of the economies of the BRICS. A special role in this context are to invite participation of an insurance companies, private pension funds. It is important to note that the pension assets, and the funds accumulated in insurance companies' long-term, life insurance contracts are key to long-term investment resources. In particular, Russia's Finance Minister, Anton Siluanov, noted that, in modern conditions, the issue of fundraising should be solved not from the state savings and budget: it is necessary to rely on private sources of investment.

Effective use of funds of institutional investors contributes to the attractiveness of investment in the economy and trade relations of BRICS. In this regard, an important direction, of work of public and private institutions, is improving the legal framework for the functioning of institutional investors, in the territories of the partner countries and the targeted use of resources within agreed initiatives, based on state guarantees of projects and development programs aimed at the development of trade economic cooperation of the countries - partners.

In modern conditions of development of trade - economic cooperation of the BRICS, it seems appropriate to take into account the world experience of implementation of state programs on the basis of public - private partnerships (PPPs), as a key mechanism for modernization of strategic sectors, among the BRICS economies. There is a need for new forms of interaction between state and business, based on new technologies, transfer of competencies to address the important challenges of sustainable development. In this regard, there is an active role to play for a New Development Bank BRICS and other development banks, with the participation of BRICS as key competence centers for the development of PPP market projects. In Russia, for example, "Vnesheconombank" and its subsidiaryFederal Center for Project Finance (FCPF) - are also able to provide effective administration of the programs of development of trade - economic cooperation of the BRICS with the participation of institutional investors, in the partner countries. For the development of capital-intensive social infrastructure projects, it is necessary to apply the tools of PPPs. Insistence of the government to the government of the Russian Federation - study best domestic and foreign experience, the need to make the PPP the most important tool in the implementation of social policy of the Russian Federation, deserved the understanding and comprehensive support for development. In this regard, it seems 
appropriate to use the mechanisms of direct and indirect financing of trade and economic cooperation of BRICS.

Practice has proved that in the development of market relations, direct financing plays an important role, which can provide replenishment of financial resources of business entities without participation of financial intermediaries.

\section{Stock Markets as a Source of Direct Financing for BRICS: Analytical Approach}

Stock markets play an important role in providing the needs of business entities with the necessary resources and perform the function of direct financing (from the market) of development projects and programs. It seems appropriate to determine the characteristics of the interaction of the BRICS stock markets, in order to develop proposals aimed at optimizing the financial resources of trade and the economies of member countries. The information base of the research is the BRICS stock indices: IBOV INDEX (Brazil), CRTX INDEX (Russia), SENSEX INDEX (India), SHCOMP INDEX (China), JALSH INDEX (South Africa) and analytical platforms WEI, DES, GP, XLTP XCIT, MEMB (Bloomberg). The choice of the listed-indices for analysis is due to several reasons. The IBOV Index (IBovespa) is Brazil's main stock index, which accurately reflects the general condition of the Brazilian stock market and Latin America as a whole (liquid, densely-populated, emerging markets). Similarly, for example, the SENSEX index is the underlying index of the Bombay Stock Exchange in India. Thus, the most representative indices were selected from the point of view of industry representation (in the context of the national economies of the BRICS countries), the dynamics of macroeconomic processes and the construction of investment strategies. The selected indices show quite accurately that the focus of investment by companies, in a number of emerging markets, is manufacturing and high-tech industries, which correlates with trends in the development of trade relations. In order to solve the tasks, the key tools and functions of Bloomberg were used: WEI, DES, GP, XLTP XCIT, MEMB.

It is important to note that evaluating and comparing the structure of BRICS stock market indices, by sector of economy, in different time parameters and taking into account the sectoral "weights" of BRICS national economies, based on Global Industry Standards and their Classification (GICS) showed the relationship of BRICS stock indices and features their dynamics.

The data obtained also indicate that in the structure of the IBOV index (Brazil) by sectors of the economy, the Finance sector is the most important $(32,64 \%)$, the least - information technology (IT $0,9 \%)$. In the sectoral composition of the index, among the dominant financing sectors are Materials $13 \%$ and Energy - 12,6\% (Fig. 1).

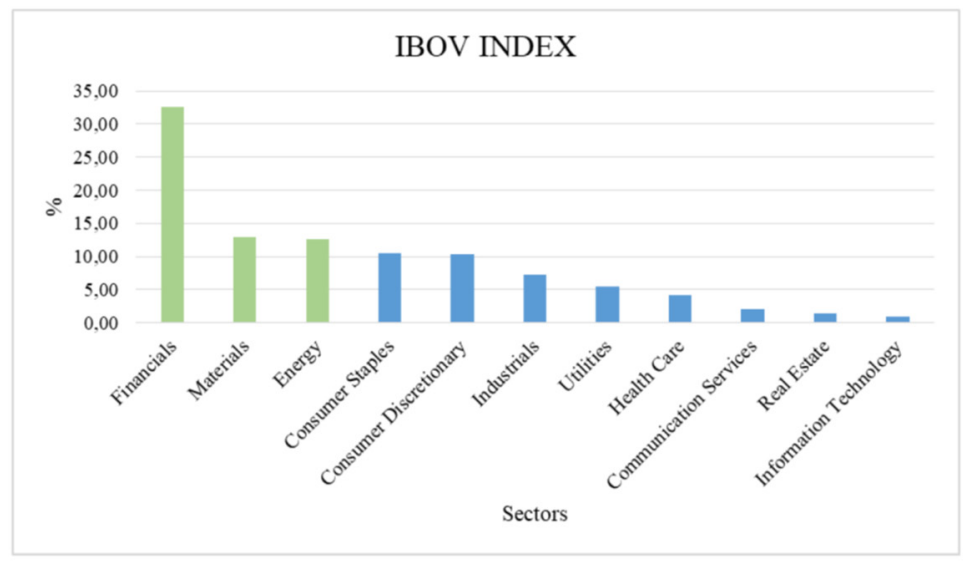

Figure 1. IBOV Stock Index Structure (Brazil) 
In the structure of the FTSE/JSE AFRICA IND 25 index, the Telecommunication technologies sector is the most significant $-43,78 \%$, and the lowest - Information Technologies - 0,27\% (Fig. 2). In addition, Energy and Utilities account for $13,12 \%$ and $10,35 \%$ of the stock market, respectively.

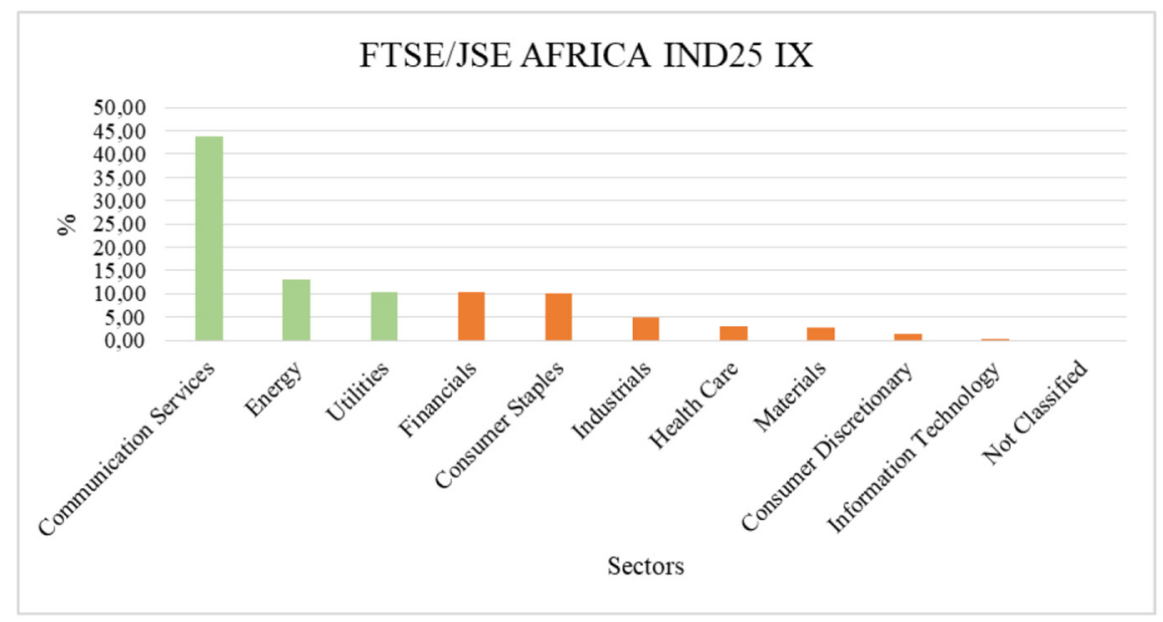

Figure 2. The structure of the FTSE/JSE AFRICA IND 25 Index (South Africa)

In the structure of the CRTX index (Russia), there is a pronounced dominance of the Energy sector $61,94 \%$, followed by Finance by $21,98 \%$ and the lowest weights in the following sectors: Telecommunication Services - 2,44\% and Consumer Goods- 1,94\% (Fig. 3).

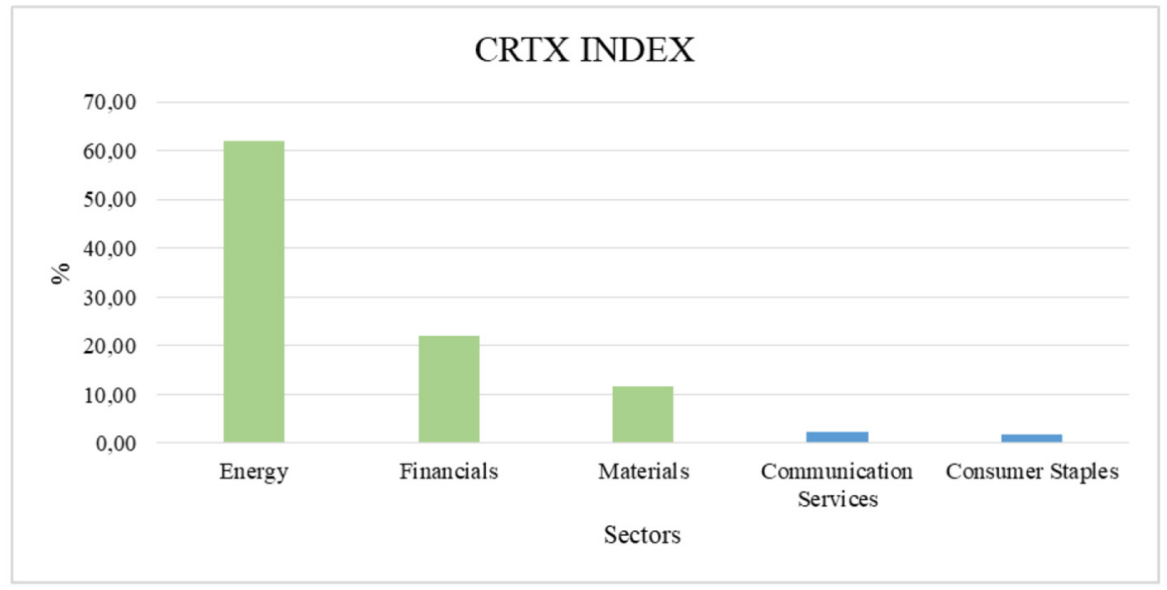

Figure 3. Structure of the CRTX Index (Russia)

Comparison of the structures of the indices of Brazil, Russia and South Africa showed the presence of structural differences, which determines the trend of diversification of the BRICS economies and creates conditions for supporting the development of production chains, taking into account the identified indicators. Thus, the Brazilian index is characterized by the dominance of the financial sector, the Russian one by the energy sector, and the African one by telecommunication technologies. It is also possible to note some structural similarities of the IBOV and CRTX indices, in which the first three positions are occupied by the Finance, Materials and Energy sectors, but in a different order and 
in different proportions in relation to other sectors. The CRTX index includes 5 sectors, which are also represented in the IBOV index. Comparison of the stock market indices IBOV and FTSE/JSE AFRICA IND 25 revealed the diversification of their structure, in contrast to the structure of the stock index CRTX (Russia). In addition, many of the sector names in the structure of the IBOV (Brazil) and FTSE / JSE AFRICA IND 25 (South Africa) indices are the same, but are in different positions, which does not exclude the possibility of interaction of partner countries in these sectors of the economy.

In turn, in the structure of the SHCOMP index (China) by sectors of the economy, the largest sector is the Finance Sector - 31,8\%, the smallest one - Communication Services - $2 \%$, and in the industrial composition of the index, among the dominant sectors of the stock market - Industry - $15 \%$ and Materials $-8,8 \%$ (Fig. 4 ).

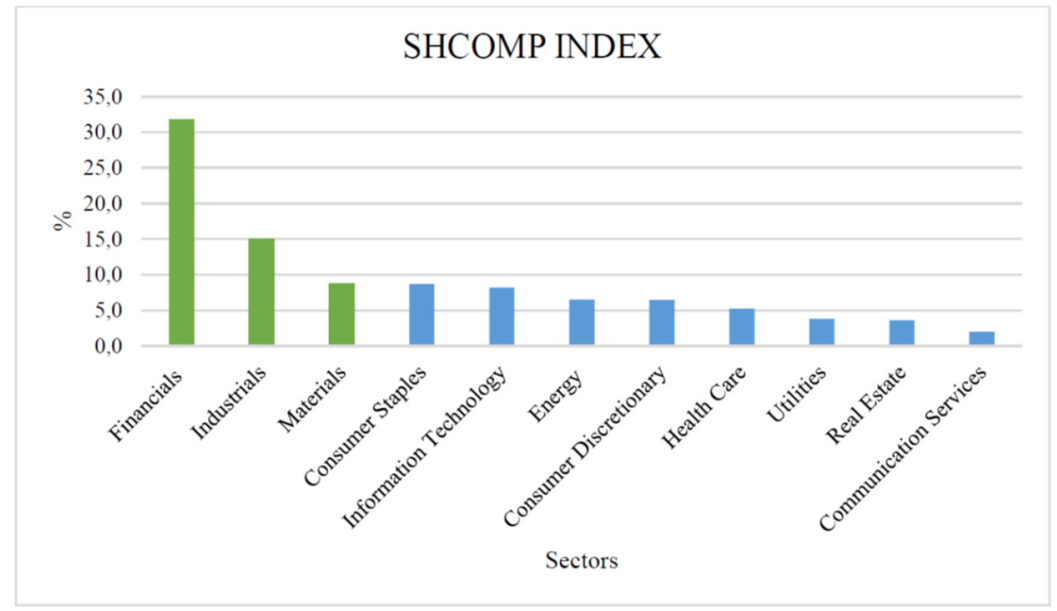

Figure 4. Structure of the SHCOMP Index (China)

In the structure of the NBEES stock index (India), the Finance Sector has the greatest weight $-41,59 \%$, the Healthcare - the smallest - 2,16\%, and Information Technology and Energy account for 13,29\% and $12,14 \%$ of the stock market shares, respectively (Fig. 5).

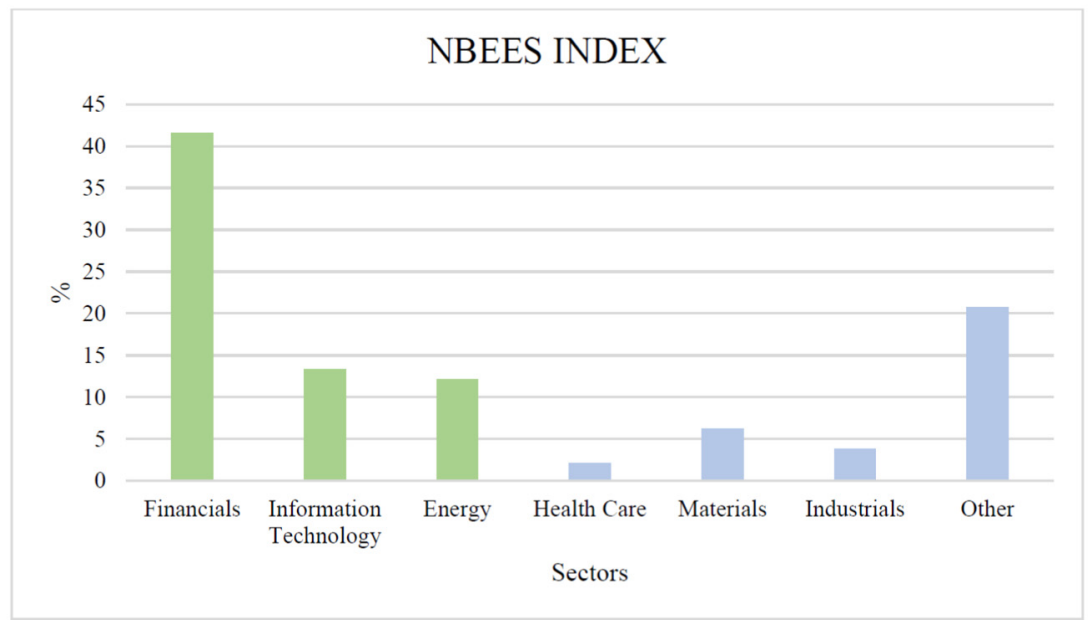

Figure 5. Structure of the NBEES Index (India) 
When comparing the structures of the stock indices of China and India, it seems possible to draw a conclusion about their similarity. So, for both indices, the dominance of the financial sector is characteristic. However, some structural differences are noted. For example, in the Indian stock index, Information Technology and Energy occupy a leading position among all sectors of the economy, while in the Chinese - the same industries have a much smaller share.

Analysis of the structure of the BRICS financial market indices showed the presence of direct financing (from the market) of the economic activity of BRICS economic entities, in key sectors of the economies of the member countries. The harmonization of direct financing and preferences, provided to BRICS business entities, helps to accumulate financial resources, expand the use of national currencies in ensuring the economic ties of partner countries and create favorable conditions for optimizing the process of sustainable development of national economies.

In turn, a comparison of the dynamics and correlation of the BRICS stock market indices revealed their interconnection and interdependence for individual time periods. For example, in the considered five-year period of time (2015-2020), the presence of a positive correlation of the stock indices IBOV (Brazil) and CRTX (Russia) (Fig. 6) was revealed. The correlation coefficient is 0,58 , which indicates the presence of a direct relationship of medium strength. It is also important to note the manifestation of a trend of some cyclicality in the dynamics of indicators and a change in the correlation relationship, which increases over individual medium-term periods. So, for example, in the period 2015-2016, an almost complete coincidence and synchronism of the dynamics of stock indices was recorded, which indicates their high correlation.

Since 2014, there has been a significant decrease in the indices of Brazil and Russia. For the Brazilian index, such dynamics is due to the recession of the Brazilian economy (in 2015, the maximum decline in 35 years), the deepening political crisis in the country, the corruption situation around the state-owned oil company Petrobras, and an increase in the budget deficit. A significant decrease in the cost of hydrocarbons also negatively affected the dynamics. The fall of the Russian stock index over a similar period of time is due, in particular, to a decrease in world oil prices, simultaneously with the currency crisis, as well as sanctions pressure. However, an overall upward trend was then observed.

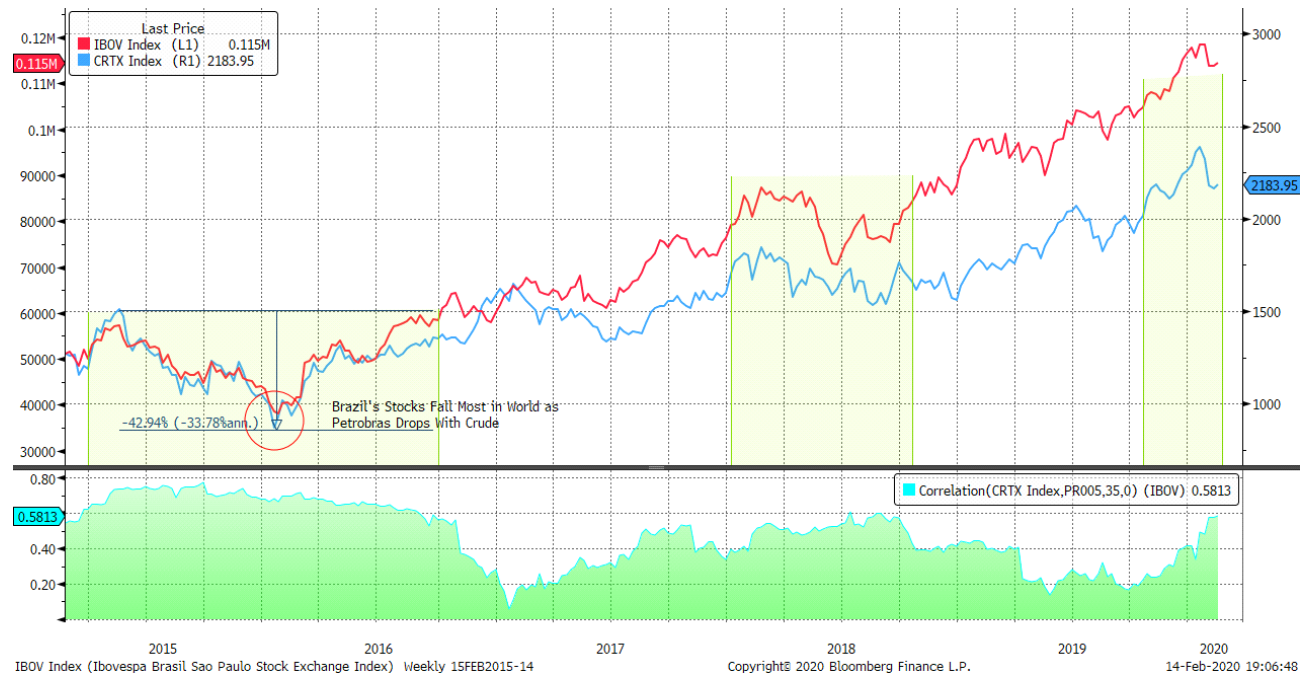

Figure 6. Comparison of the dynamics of the IBOV and CRTX indices

At the same time, when choosing an annual, rather than a weekly, breakdown and increasing the analyzed time period to 10 years (2010-2020), the IBOV and CRTX stock indices showed a decrease in 
the correlation coefficient to o,54, while a direct relationship is still observed medium strength indices (Fig. 7).

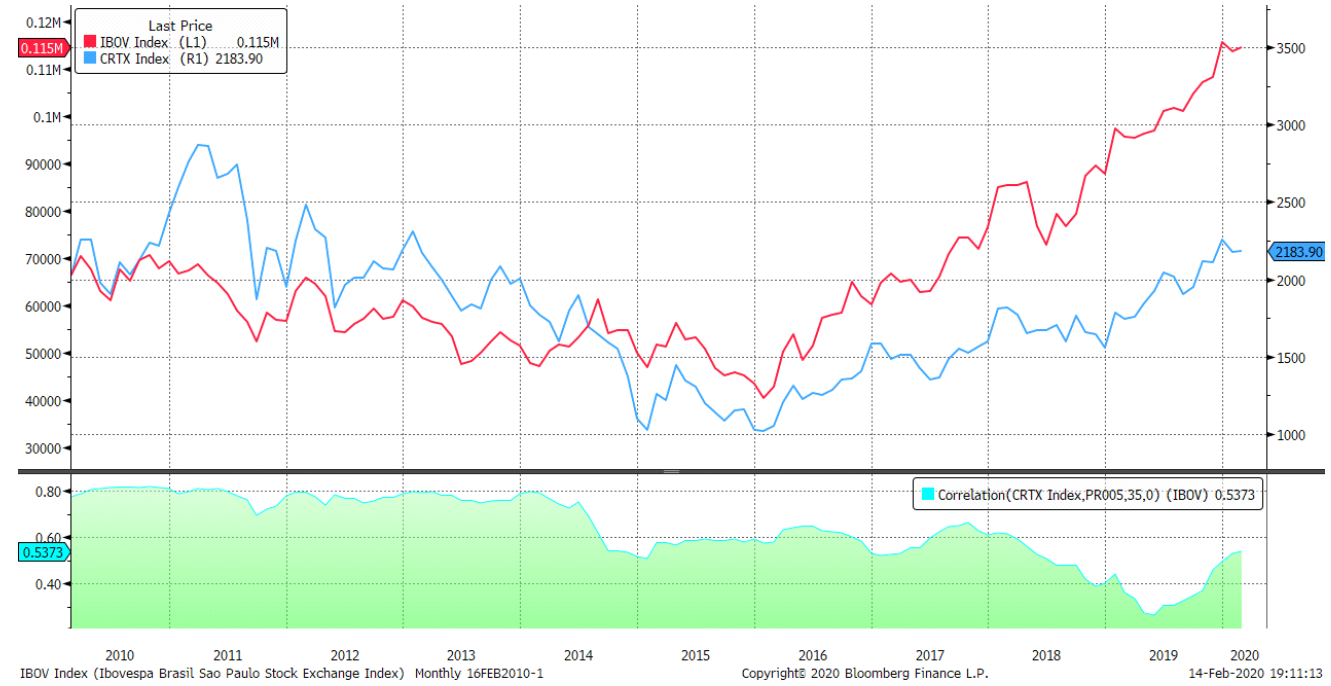

Figure 7. Comparison of the dynamics of the IBOV and CRTX indices (annually, 10 years)

In turn, a comparative analysis of the dynamics of the stock indices IBOV and INDI25 showed the following result (Fig. 8).

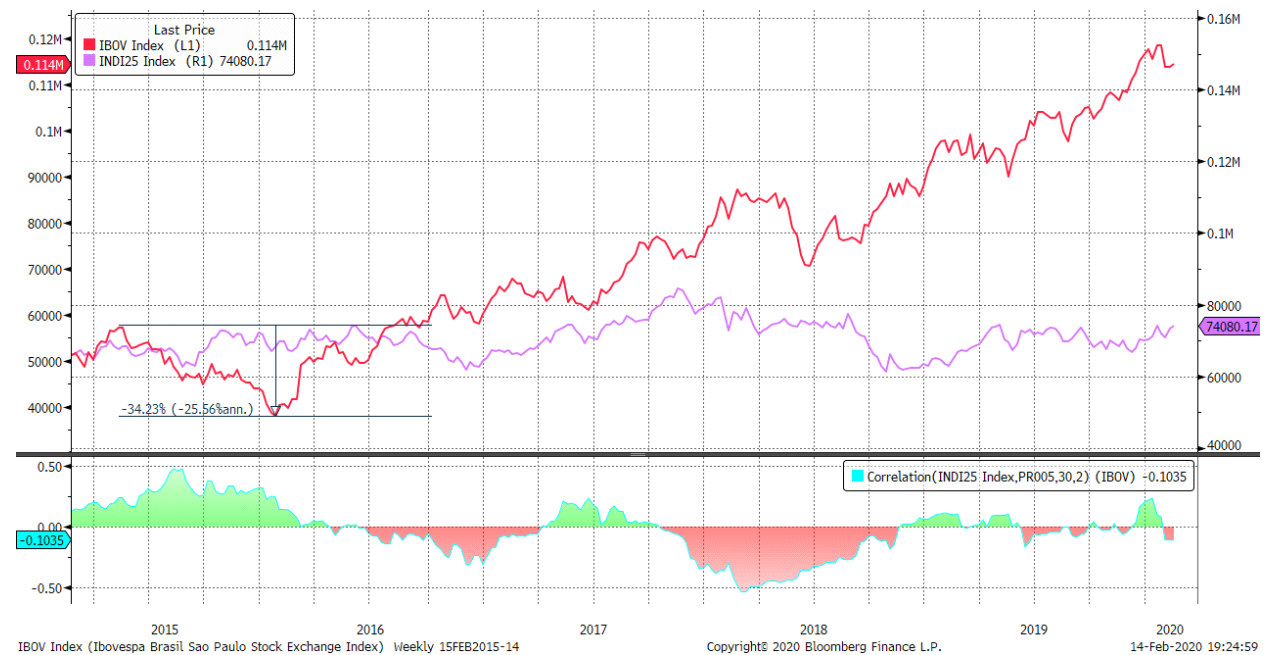

Figure 8. Dynamics of IBOV and INDI25 indices

In the considered five-year period of time (2015-2020) with lag $2(L A G=2)$ for the IBOV (Brazil) and INDI25 (South Africa) indices, there is practically no correlation dependence (the correlation coefficient is - o,10), their relationship is extremely weak, insignificant, while in separate parameters the opposite (Fig. 9).INDI25 is an oscillator of the 25 most expensive industrial stocks in South Africa. 
The slowdown in the dynamics of the stock index and macroeconomic indicators in Africa in 2015-2016, in particular, took place against the background of a general slowdown in the growth rate of the world economy, a further fall in prices for raw materials and fuel products.

According to the results of the analysis, periodicity in the correlation dynamics of stock indices was also revealed. For example, in the period 2015-2016, communication increased (and also in 20162017), dependence was weakening and, after 2017, the discrepancy increased significantly, which coincides with the tightening of financial market regulation in the BRICS countries under consideration.

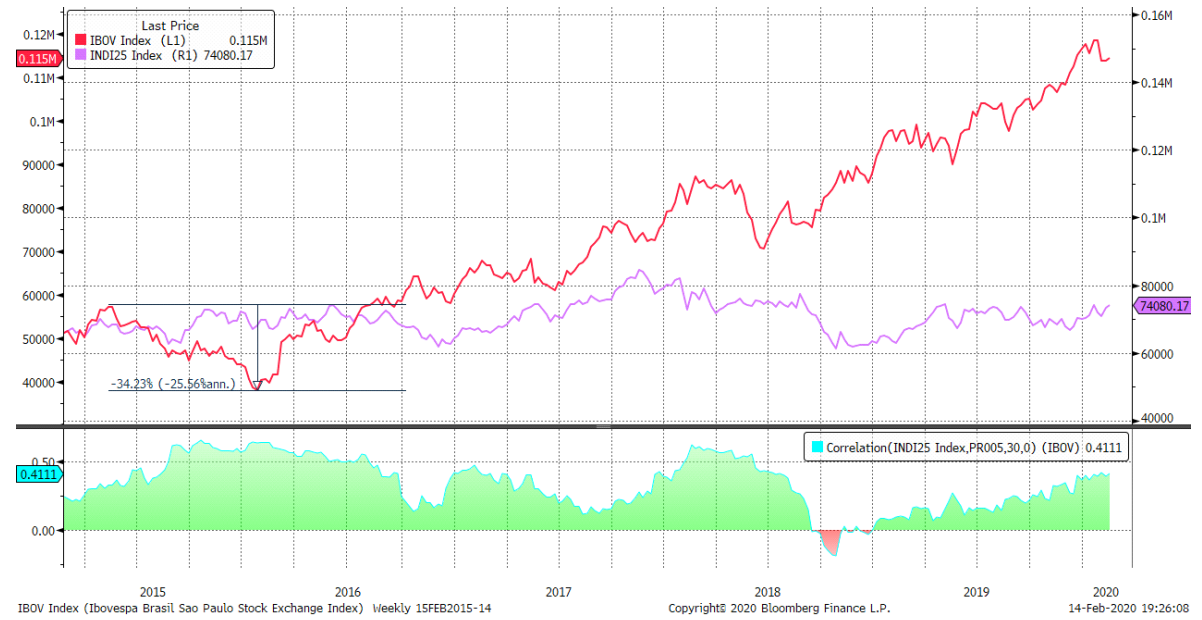

Figure 9. Dynamics of the IBOV and INDI25 indices

With a decrease in the lag value from 2 to o $(\mathrm{LAG}=0$ ) for the IBOV (Brazil), and INDI25 (South Africa) indices, the correlation coefficient increases to o,41; moreover, in almost the entire considered time interval, the relationship is direct, with narrowness being below average.

Comparison of the stock market indices of Russia and South Africa revealed the following trend (Fig. 10).

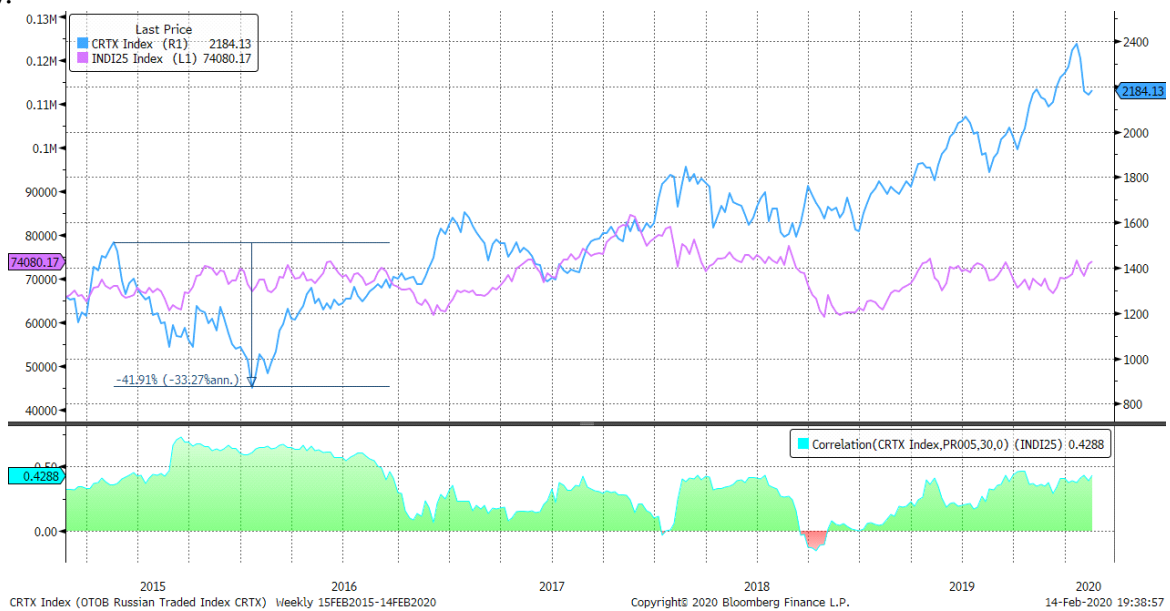

Figure 10. Dynamics of CRTX and INDI25 indices 
In the considered five-year time period (2015-2020) with a lag of o $(\mathrm{LAG}=\mathrm{o})$ for the indices CRTX (Russia) and INDI25 (South Africa), there is a direct relationship, the tightness of communication is slightly below average (the correlation coefficient is 0,43 ). The discrepancy in dynamics most significantly increased in the period 2018-2019, which was the result of intergovernmental measures to support the business entities of Russia and South Africa in the indicated period of time.

In turn, with an increase in the lag value from o to $2(\mathrm{LAG}=2)$ for the CRTX and INDI25 indices, a decrease in the correlation coefficient is noted, with the transition of its value to the region of negative values $(-0,14)$, and there are alternating periods of increase and decrease interdependence (Fig. 12).

By comparing the dynamics of the stock indices IBOV (Brazil), FTSE/JSE AFRICA IND 25 (South Africa) and CRTX (Russia) and comparing the pairwise correlation, a generally pronounced decrease in the interdependence was found. The most closely-related are the IBOV (Brazil) and CRTX (Russia) indices, which is a consequence of the similarity of their product structure by economic sectors and the dynamics of world energy prices, as the Materials and Energy sectors, which occupy the leading structural positions of the indices of the financial markets of these countries, are the most sensitive in the face of changing market conditions.

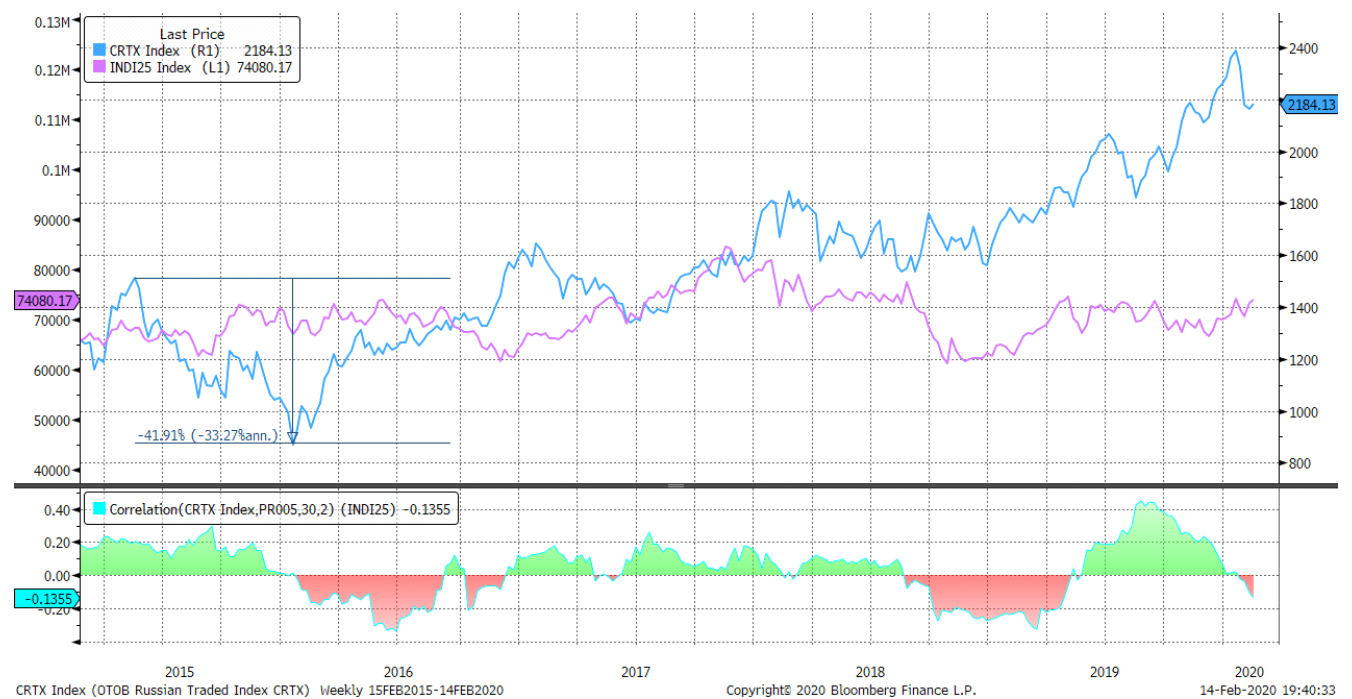

Figure 11. Comparison of CRTX Index with INDI25 Index dynamics $(\mathrm{LAG}=\mathbf{2})$

The structural proportions of economic sectors, implemented in the stock indices under consideration, are presumably related to the cyclical nature of the relationships. However, when using weekly breakdowns over a 5-year period, the stability of the correlation interdependence was observed over the medium term. Over the course of the 5 -year period under review, a positive correlation is observed, at which the average coefficient is 0,51 . The most synchronized dynamics of the indices was in the 2015-2017 period, which generally coincides with the results obtained earlier for the IBOV index and INDI25 indices: at the beginning of the analyzed period, there is an average correlation, or above the average, and then there are discrepancies. 


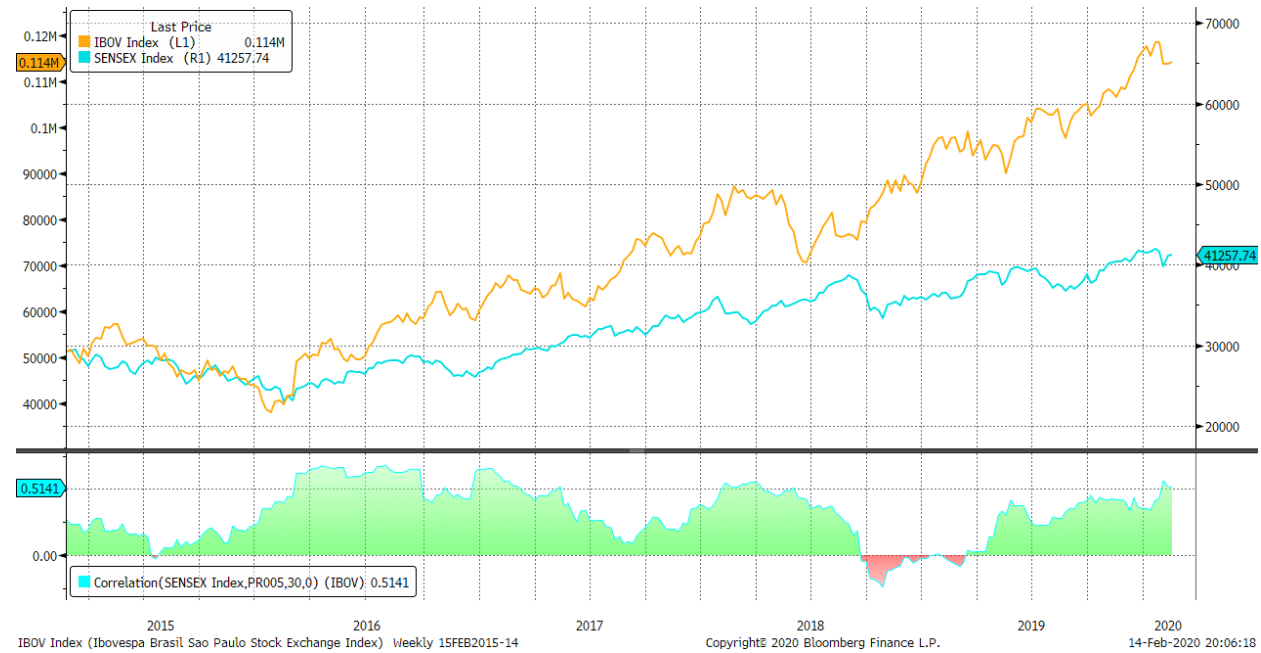

Figure 12. Comparison of the IBOV Index and SENSEX Index

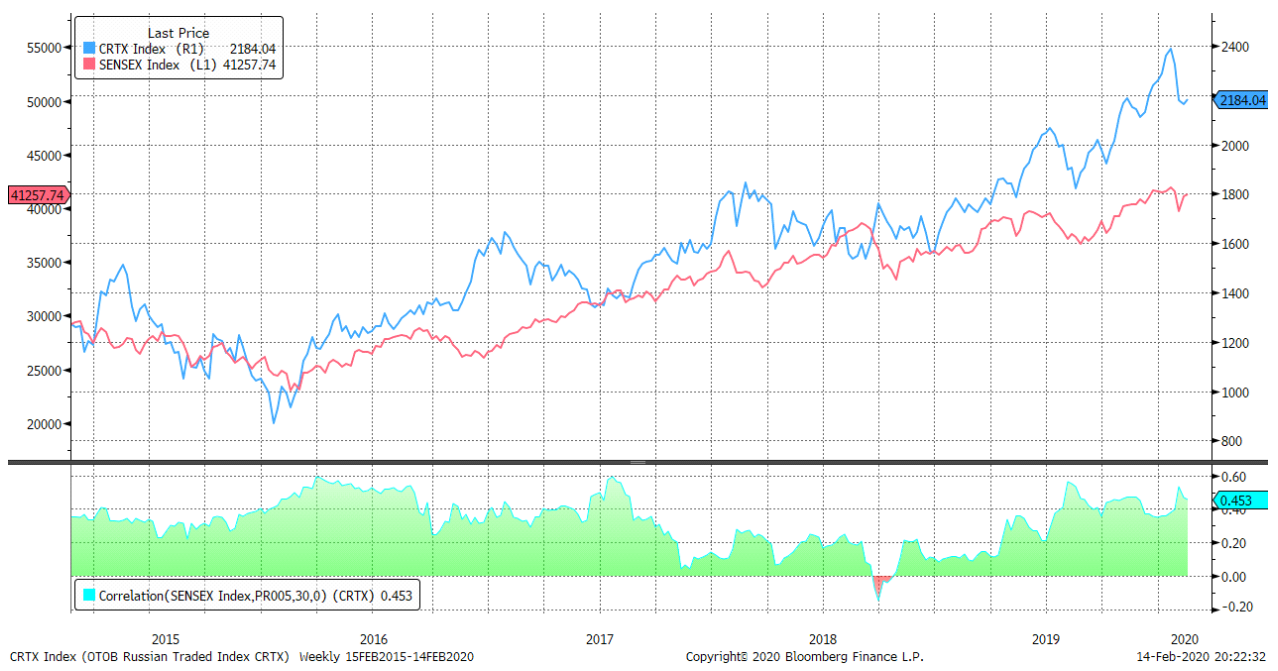

Figure 13. Comparison of CRTX Index and SENSEX Index

Evaluation of the data also showed the presence of a direct (positive) correlation of stock indices, with a maximum value of the coefficient above 0,5 (Fig. 13). India's economy has become the fastest growing in the world, ahead of China in 2015 and 2018. India has managed to become a major exporter of IT services, an important center of technology outsourcing for multinational corporations and a supplier of relevant specialists to leading countries of the world. This is reflected both in the structure of the Indian stock index and in its dynamics over the period under review. In some cases, there is a relationship between stock indices at the beginning of the period under review, followed by a longterm decrease in the relationship between the considered pairs of BRICS stock exchange indices (Fig. 14, Fig. 15). Among Asian stock indices, the Shanghai Stock Exchange's SSE index showed the most volatility. This is the result, in particular, of the formation, in 2015, of a financial bubble in the market and its subsequent liquidation. 


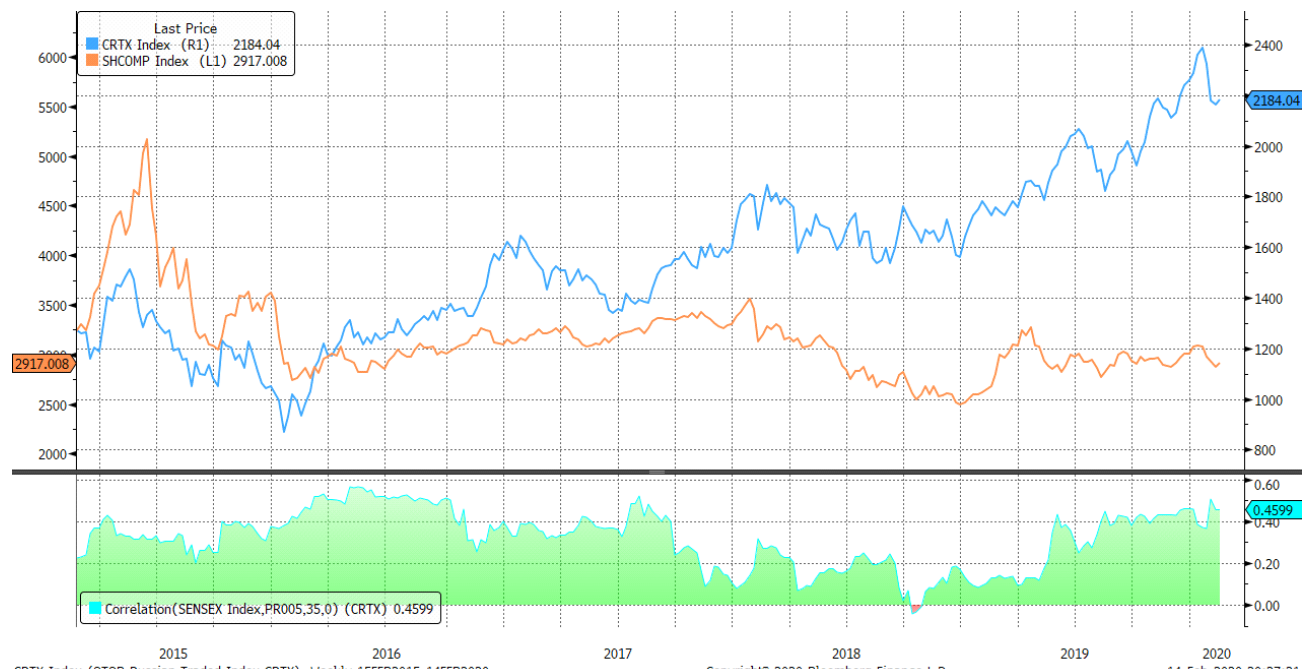

Figure 14. Comparison of CRTX and SHCOMP indices

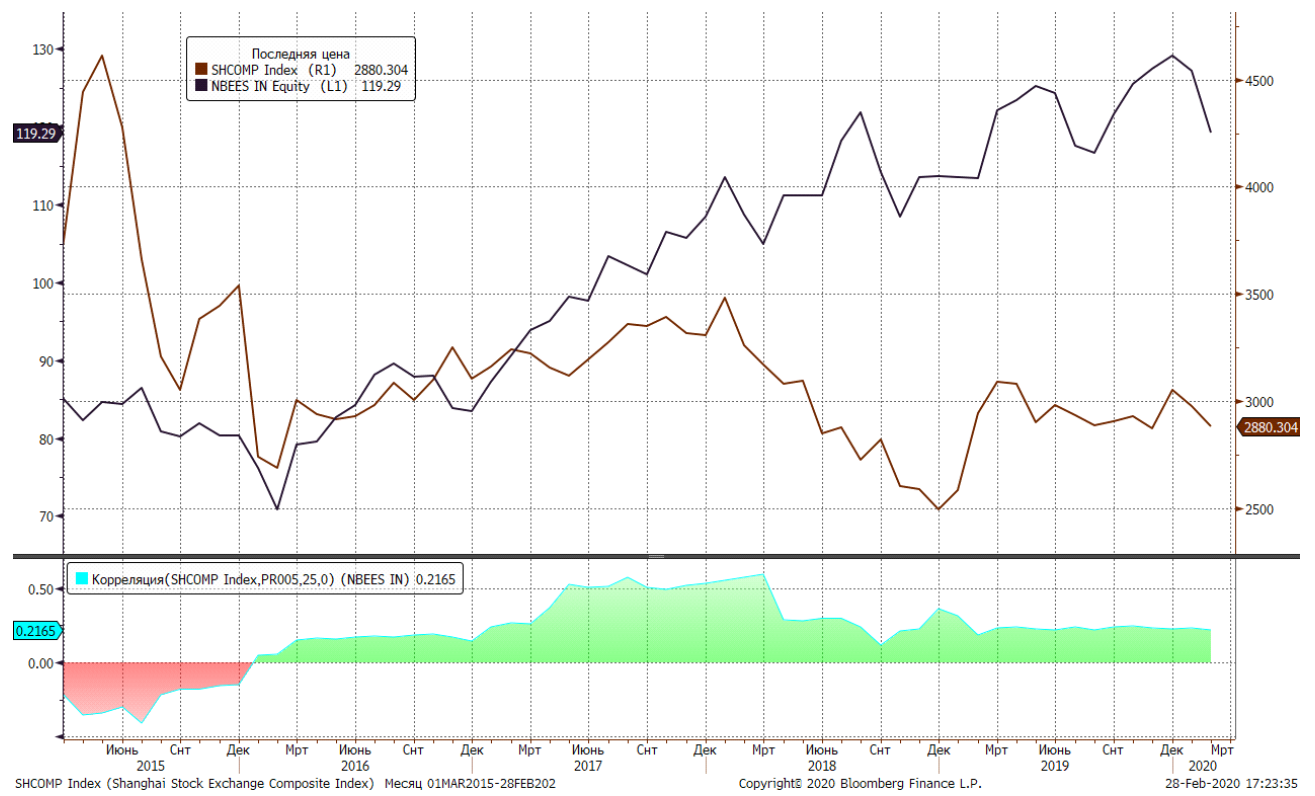

Figure 15. Comparison of the dynamics of SHCOMP and NBEES indices

In the considered five-year period of time $(2015-2020)$, the presence of a positive correlation was revealed.

Additional analysis using the (XCIT) function showed that there is a direct relationship between the IBOVE Index and CRTX Index (Brazil-Russia), IBOVE Index and INDI25 Index (Brazil - South Africa), with the determination coefficient averaging 0,55 , which is a consequence of the implementation of financial policies in the BRICS member countries.

The results allow us to conclude that it is necessary to optimize the interstate support of BRICS 
projects and programs of trade and economic cooperation, in the difficult period of overcoming the consequences of the global epidemiological threat. Flexible conditions for interaction between the parties, the provision of preferences for BRICS business entities in the implementation of business processes will create conditions for expanding instruments for direct and indirect financing of key sectors of the BRICS economies and the development of trade.

\section{Conclusion}

The conducted analysis confirmed the need for the formation of short-and long-term strategies for BRICS economic partnership in trade and investment. It is noted that the priorities of long-term strategy for BRICS is strengthening the position of countries in the global economy. Evaluation of indices of stock markets of the BRICS showed that the absence of a coherent long-term strategy for BRICS economic partnership contributes to the accumulation of the resources necessary to address important strategic objectives, in order to achieve sustainable, inclusive development. In turn, the short-term strategy promotes the implementation of mechanisms of joint action in the agreed period of time. Short-term strategy takes into account the volatility of the world economy and finance, the strategic interests of partner countries in the near future. The proposed approach: inter-state support of business entities of the BRICS, creates favorable conditions for the effective solution of problems and adaptation of the BRICS to changes in the global economic and trade landscape.

Exhibitions, trade fairs involving BRICS on a regular basis contribute to the strengthening of partnerships in promoting development, transfer of competences and broadening of cooperation between the parties through dialogue and exchange of experience in issues of multilateral cooperation.

It seems reasonable to increase the participation of development banks with the participation of BRICS and institutional investors of all forms of ownership in the processes of stimulation of the partnerships of the member countries of the interstate association.

Harmonization of trade and economic contacts between economic entities of the BRICS will expand cooperation between the parties, both in traditional fields and areas due to the peculiarities of the world economic development in the short and longer term.

he results of the analysis, of the stock markets of the BRICS, contribute to the formation of the main principles and priorities for funding projects and development programs of strategic interest to member countries.

In order to expand the resource base of economic and trade cooperation of economic entities of the BRICS, it is advisable to increase the interaction of the New Development Bank, BRICS development banks with the participation of BRICS, which perform the function of financial intermediaries (indirect financing) and are participants of the stock markets of the BRICS (direct funding).

In order to minimize the risk of trade - economic contacts, economic actors of the BRICS, it seems appropriate to speed up the process of harmonization of regulation of financial relations of member countries.

\section{References}

Arapova E.Ya. (2016) Prospects for Economic Integration within BRICS. Russian Foreign Economic Journal, no 2, pp. $32-47$.

Arapova E.Ya., Chkoniya A.E. (2016) BRICS trade potential: problems and prospects. National Interests: Priorities and Security, no 7, pp. 152-164.

Bank of Russia (2017) Meeting of finance ministers and Central Bank governors of the BRICS countries. Available at: https://www.cbr.ru/today/ms/inf_2017-03-20/ (accessed 15 March 2019).

BRICS (2016) Leaders' Declaration. Available at: http://www.kremlin.ru/supplement/5139 (accessed 29 March 2019).

BRICS (2017) Leaders' Declaration. Available at: http://d-russia.ru/wp-content/uploads/2017/o9/2017-o905_BRICS_Declaration.pdf (accessed o5 April 2019). 
BRICS (2018) Leaders' Declaration. Available at: http://www.kremlin.ru/supplement/5323 (accessed o5 April 2019).

Gusarova S.A. (2017) The development of electronic commerce in the BRICS countries. Economic sciences, no 11 (156), pp. 34-42.

International Trade Center (2018) Trade Map. Available at: https://www.trademap.org (accessed o3 April 2019).

National Committee on BRICS Research (2018) The ministers of economy and foreign trade of BRICS determined the vector of further development of the association. Available at: http://nkibrics.ru/posts/show/5b4f5a9862726905317500oo (accessed 29 March 2019).

Tinbergen J. (1962) Shaping the World Economy: Suggestions for an International Economic Policy. New York: Twentieth Century Fund

UNCTAD (2018) Publications Library. Available at: https://unctad.org/en/Publications Library/tdr2018overview_ru.pdf (accessed 10 April 2019).

UNIDO (2015) BRICS Trade, Economic and Investment Cooperation Roadmap for the period up to 2020. Available at: http://www.unido.ru/upload/files/d/dorohznaja_karta_briks.pdf (accessed o3 April 2019).

World Bank Group (2017) World Development Indicators. Available at: https://databank.worldbank.org/data/reports.aspx (accessed 25 March 2019).

World Bank Group (2018) Logistics Performance Index. Available at: https://lpi.worldbank.org/international/scorecard (accessed 15 April 2019).

Yarygina I.Z. (2013) Public-private partnership of the BRICS member countries as a risk reduction factor for the global economy. Economy. Taxes. Law, no 4, pp. 56-59. 